\title{
Genome-wide identification of CLE gene family and their potential roles in bolting and fruit bearing in cucumber (Cucumis sativus L.)
}

Nannan Qin, Yang Gao, Xiaojing Cheng, Yang Yang, Jiang Wu, Jinyao Wang, Sen Li and Guoming Xing*

\begin{abstract}
Background: Signal peptides are essential for plant growth and development. In plants, biological processes including cell-cell communication, cellular proliferation and differentiation, cellular determination of selfincompatibility, and defensive responses, all depend heavily on peptide-signaling networks such as CLE (CLAVATA3/ Embryo surrounding region-related). The CLEs are indispensable in different periods of plant growth and development, especially in maintaining the balance between proliferation and differentiation of stem cells in various meristematic tissues.

The working system of CLE genes in cucumber, an important economical vegetable (Cucumis sativus L.), has not been fully studied yet. The distributional patterns of chromosome-level genome assembly in cucumber provide a fundamental basis for a genome-wide comparative analysis of CLE genes in such plants.
\end{abstract}

Results: A total of 26 individual CLE genes were identified in Chinese long '9930' cucumber, the majority of which belong to unstable short alkaline and hydrophilic peptides. A comparative analysis showed a close relationship in the development of CLE genes among Arabidopsis thaliana, melon, and cucumber. Half of the exon-intron structures of all CSCLEs genes are single-exon genes, and motif 1, a typical CLE domain near the C-terminal functioning in signal pathways, is found in all cucumber CLE proteins but CSCLE9. The analysis of CREs (CisRegulatory Elements) in the upstream region of the 26 cucumber CLE genes indicates a possible relationship between CSCLE genes and certain functions of hormone response elements. Cucumber resulted closely related to Arabidopsis and melon, having seven and 15 orthologous CLE genes in Arabidopsis and melon, respectively. Additionally, the calculative analysis of a pair of orthologous genes in cucumber showed that as a part of the evolutionary process, CLE genes are undergoing a positive selection process which leads to functional differentiation. The specific expression of these genes was vigorous at the growth and development period and tissues. Cucumber gene CLV3 was overexpressed in Arabidopsis, more than half of the transformed plants in T1 generation showed the phenomena of obvious weakness of the development of growing point, no bolting, and a decreased ability of plant growth. Only two bolted strains showed that either the pod did not develop or the pod was short, and its development was significantly inferior to that in the wild type.

(Continued on next page)

\footnotetext{
*Correspondence: xingguoming@163.com; saulisen@163.com

College of Horticulture, Shanxi Agricultural University, Taigu, China
}

C C The Author(s). 2021 Open Access This article is licensed under a Creative Commons Attribution 4.0 International License, which permits use, sharing, adaptation, distribution and reproduction in any medium or format, as long as you give appropriate credit to the original author(s) and the source, provide a link to the Creative Commons licence, and indicate if changes were made. The images or other third party material in this article are included in the article's Creative Commons licence, unless indicated otherwise in a credit line to the material. If material is not included in the article's Creative Commons licence and your intended use is not permitted by statutory regulation or exceeds the permitted use, you will need to obtain permission directly from the copyright holder. To view a copy of this licence, visit http://creativecommons.org/licenses/by/4.0/ The Creative Commons Public Domain Dedication waiver (http://creativecommons.org/publicdomain/zero/1.0/) applies to the data made available in this article, unless otherwise stated in a credit line to the data. 


\begin{abstract}
(Continued from previous page)
Conclusions: In this study, 26 CLE genes were identified in Chinese long '9930' cucumber genome. The CLE genes were mainly composed of alkaline hydrophilic unstable proteins. The genes of the CLE family were divided into seven classes, and shared close relationships with their homologs in Arabidopsis and melon. The specific expression of these genes was evaluated in different periods of growth and tissue development, and CLV3, which the representative gene of the family, was overexpressed in Arabidopsis, suggesting that it has a role in bolting and fruit bearing in cucumber.
\end{abstract}

Keywords: CLE peptides, Cucumber, Gene family, Phylogenetic analysis

\section{Background}

Signal peptides are short peptide chains that guide the transfer of newly synthesized proteins to the secretory pathway, and are generally 5-30 amino acids in length. Plant small signaling peptides play important roles in eukaryotic growth and development process, for instance, stress response [1-3], apical meristem maintenance [4-6], vascular bundle development [7], stomata development [8], reproductive growth [9], cell division [10], and mineral element absorption [11], as well as cell-cell communication, self-incompatibility determination and other molecular-level roles [12]. The CLAV ATA3(CLV3)/EMBRYO SURROUNDING REGION (CLE) peptides, a better studied class of signal peptide molecules, consist of 12 or 13 amino acids, including hydroxylated proline residues that may or may not contain sugar modifications, and function in a non-cellautonomous fashion. They function in the extracellular space as intercellular signaling molecules and bind to cellular surface receptor-like proteins to transmit a signal. The CLE polypeptide hormones play a key role in many important processes of higher plant growth and development, especially in maintaining the balance between proliferation and differentiation of stem cells in different meristematic tissues [13, 14]. The CLE peptide hormones, in regulating stem meristem of transcription factors in the cell nucleus WUS (WUSCHEL), promote the expression of stem cell marker genes $C L V 3$, maintain stem cell properties, while the expression of CLV3 inhibiting WUS transcription level promote stem cell differentiation, and form a very precise feedback control loop that controls the number of stem cells in the stem meristem [13]. In the distal root meristem, a self-regulating interaction feedback loop is also formed between the ACR4-CLE40-mediated signal and the WUS family transcription factor WOX5 to regulate the proliferation and differentiation of the distal root meristem [13, 14]. Vascular cambium, as the initial center of plant vascular phylogeny, has the characteristics of pluripotent stem cells. Hirakawa, Fisher, Turner et al. [15-17] found that there is a regulatory mechanism whereby vascular cambium cell division is regulated by the PXY/TDR gene expressed in the Arabidopsis cambium cells and the
CLE41/ TD1F gene expressed in the phloem element differentiation inhibitory factor. Hirakawa et al. [16] found that vascular bundles of Arabidopsis that overexpressed CLE41 and CLE44 were fractured, resulting in excessive division of procambium cells and significant enlargement of vascular regions. Gene CLE41/TDIF expressed specifically in the phloem of Arabidopsis can promote the proliferation of procambium cells and inhibit the differentiation of procambium cells into conduit molecules. Except for CLE41/44 and CLE42, all other CLE polypeptides, including CLV3, do not perform this function. The PXY/TDR mutation of the receptor of CLE41/44 would make the procambium cells disorientated during division, reducing the differentiated xylem and phloem cells, while retaining more undifferentiated procambium cells [15-17]. The expression level of WUS homologous gene WOX4 in the procambium was shown to be regulated by CLE41/44 [16].

Cucumber (Cucumis sativus L.; $2 \mathrm{n}=2 \mathrm{x}=14$ ), is an economically important vegetable crop worldwide. It is consumed in the immature or mature, fresh or processed form. Cucumber genome was sequenced early in 2009 due to its small genome size (around $367 \mathrm{Mb}$ ) and agricultural importance, providing insight into traits such as its sex expression, disease resistance, biosynthesis of cucurbitacin, and 'fresh green' odor [18]. This draft genome was assembled using low-coverage Sanger sequences and high-coverage short Illumina sequences over a 70-fold genome coverage for the Chinese long inbred line '9930', 72.2-fold genome coverage. For years, researchers have shown interest in whole-genome and whole-transcriptome sequencing that resulted in several versions of the cucumber genome and provided genetic information. Scaffold assemblies of three cucumber lines (Chinese long'9930', Gy14 [19], and B10) are available so far. Mainstream genome assembly and gene annotation of cucumber cultivar Chinese long '9930' have been updated to version 3 . Version 3 of the cucumber genome was assembled using PacBio long reads, 10X Genomics, and high-throughput chromosome conformation capture (Hi-C) data. This accurate genome assembly, containing 174 contigs with a total length of $226.2 \mathrm{Mb}$ and an N50 of $8.9 \mathrm{Mb}$, identified 1078 novel genes, including 239 
tandemly-duplicated genes and 1374 full-length long terminal retrotransposons [20]. Additionally, many cucumber genome and transcriptome databases were constructed to provide user-friendly query interfaces for genomic research and breeding. In 2012, the first draft genome of melon became available. The double-haploid line DHL92 was sequenced and $375 \mathrm{Mb}(83.3 \%)$ of melon genome has been assembled, including 27,427 protein-coding genes. Since the ancient eudicot triplication, the recent whole-genome duplications were absent in the melon lineage, which might have resulted in the increased size of melon genome compared with cucumber [21]. The genome-wide identification of CLE genes in melon and further comparison with cucumber homologs will help elucidate the evolutionary pattern within cucurbit species. The available cucumber genome assembly and abundant tools have accelerated genomic research, including gene family analysis through a bioinformatic approach. Genome-wide gene family analysis has been implied in numerous cucumber gene families, including MADS-box [22], SWEET [23], auxin response factor [24], lipoxygenase [25], calciumdependent protein kinase [26], metacaspase [27], glutathione peroxidase [28], and aquaporin [29], but the specific biological and functional roles of the CLE genes in cucumber remain unknown.

The present study focuses on a genome-wide analysis of CLE genes in cucumber. We analyzed the exon-intron structure, gene phylogeny and synteny, and the tissuespecific expression of the identified $C L E$ genes, as well as heterologous overexpression of cucumber $C L V 3$ gene in Arabidopsis. The objective of this study was to provide insights into the genetic network of signaling peptides in cucumber and other cucurbit crops which should in the future facilitate improvement in yield, nutritional value, and commercial quality.

\section{Results}

Genome-wide identification of CLE genes in cucumber

The genome-wide search for CLE genes in cucumber was done using alignment. We first downloaded the known CLE proteins of Arabidopsis to self-construct a CLE Markov model. By scanning all 24,317 cucumber coding proteins in the genome assembly version 3 using the designed CLE Markov model, we identified 26 CLE transcription factors (S1 Table). Manual check revealed well conserved CLE transcription factors (referred by the term 'CsCLE' with a serial number and sorted by the Evalue of the CLE domain; Table 1). Many cucumber CLE peptides are short peptides (90 amino-acid long) except CsCLE24 (1021 amino acids), CsCLE5 (416 amino acids), and CsCLE6 (404 amino acids). The molecular weight of the cucumber CLE proteins ranged from 5293.84 (CsCLE9) to 113,323.11 (CsCLE24), which is very similar to those in Arabidopsis. Most cucumber CLE proteins are alkaline with a theoretical pI ranging from 7.09 (CsCLE17) to 12.11 (CsCLE10), except for one weakly acidic protein, CsCLE24 $(\mathrm{pI}=6.52)$. The CsCLE4 protein is stable whereas others are unstable. The aliphatic index of cucumber CLE proteins ranged from 49.03 (CsCLE6) to 106.78 (CsCLE17), and the GRAVY index ranged from -0.935 (CsCLE9) to 0.17 (CsCLE21).

The 26 CLE genes remained distributed across chromosomes, including 7 on chr5, 6 on chr6, 5 each on chr1 and chr2, and one each on chr3, chr4, and chr7 (Fig. 1). The CLE genes CsCLE24 and CsCLE25 were located extremely close with a short intergenic location of $1 \mathrm{~kb}$. Besides, CsCLE13 and CsCLE14 were also located in close proximity; this finding indicated that these genes might be tandemly duplicated. In addition, one gene pair, CsCLE5 and CsCLE6, with segmental duplication was found within the CsCLE family, and the identified segmental duplication gene pairs were distributed on different chromosomes in cucumber (Fig. 2).

\section{Phylogenetic relationships and divergence of cucumber CLE proteins}

In the present study, we primarily use the genome assembly of Chinese long ' 9930 '.

Only 31 CLE genes were identified (S2 Table) in this report, while a previous report showed that Arabidopsis contained $32 C L E$ genes [30]. A total of $25 C L E$ genes were identified in melon (S3 Table) using the computational approach. To understand the evolution of CLE genes in Cucurbitaceae and the model plant Arabidopsis, we compared the genes from Arabidopsis, melon, and the cucumber cultivar Chinese long '9930' (Fig. 3). These CLEs were divided based on their phylogenetic relationship into seven paraphyletic groups (Groups 1 to 7). All groups except for Group 2 and Group 6 were composed of CLEs from both cucumber and other plant species, indicating the close relationship between cucumber CLEs and those of other plants. The distribution of cucumber CLEs was uneven in these groups. Group 7 was the largest group with 12 members, accounting for nearly half of the cucumber CLEs, followed by Groups 1 and 5 containing 6 and 5 cucumber CLEs, respectively. The least represented subfamilies were Groups 2 and 6 with no cucumber CLEs.

\section{Gene structure of cucumber CLE genes}

In order to compare the cucumber genes, their exonintron structures were predicted (Fig. 4). The phylogenetic tree was constructed by the Maximum-Likelihood method using the conserved protein sequence of the cucumber $C L E$ genes. Fourteen $C L E$ genes were singleexon genes, ten were double-exon genes, and one was a 


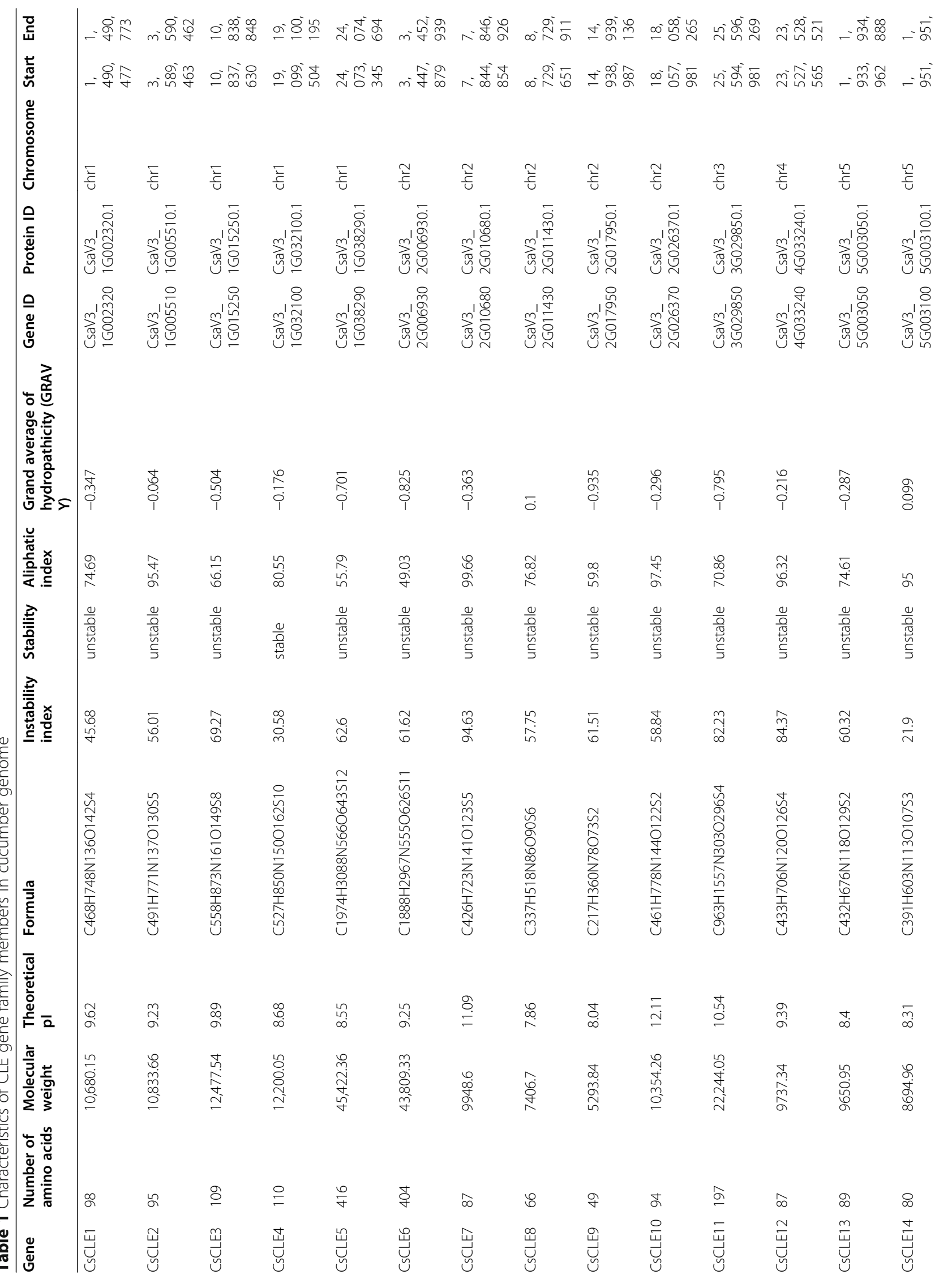




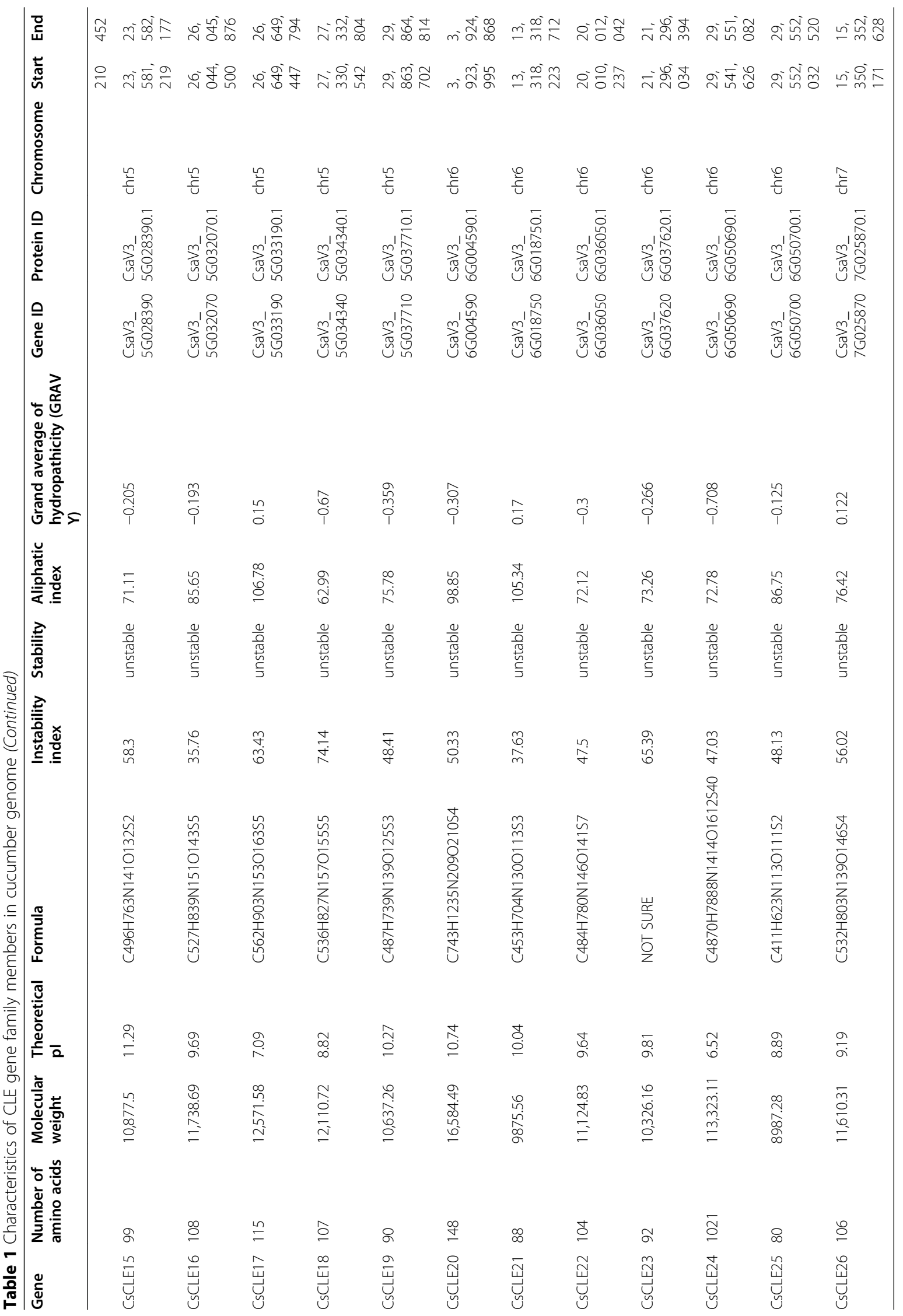




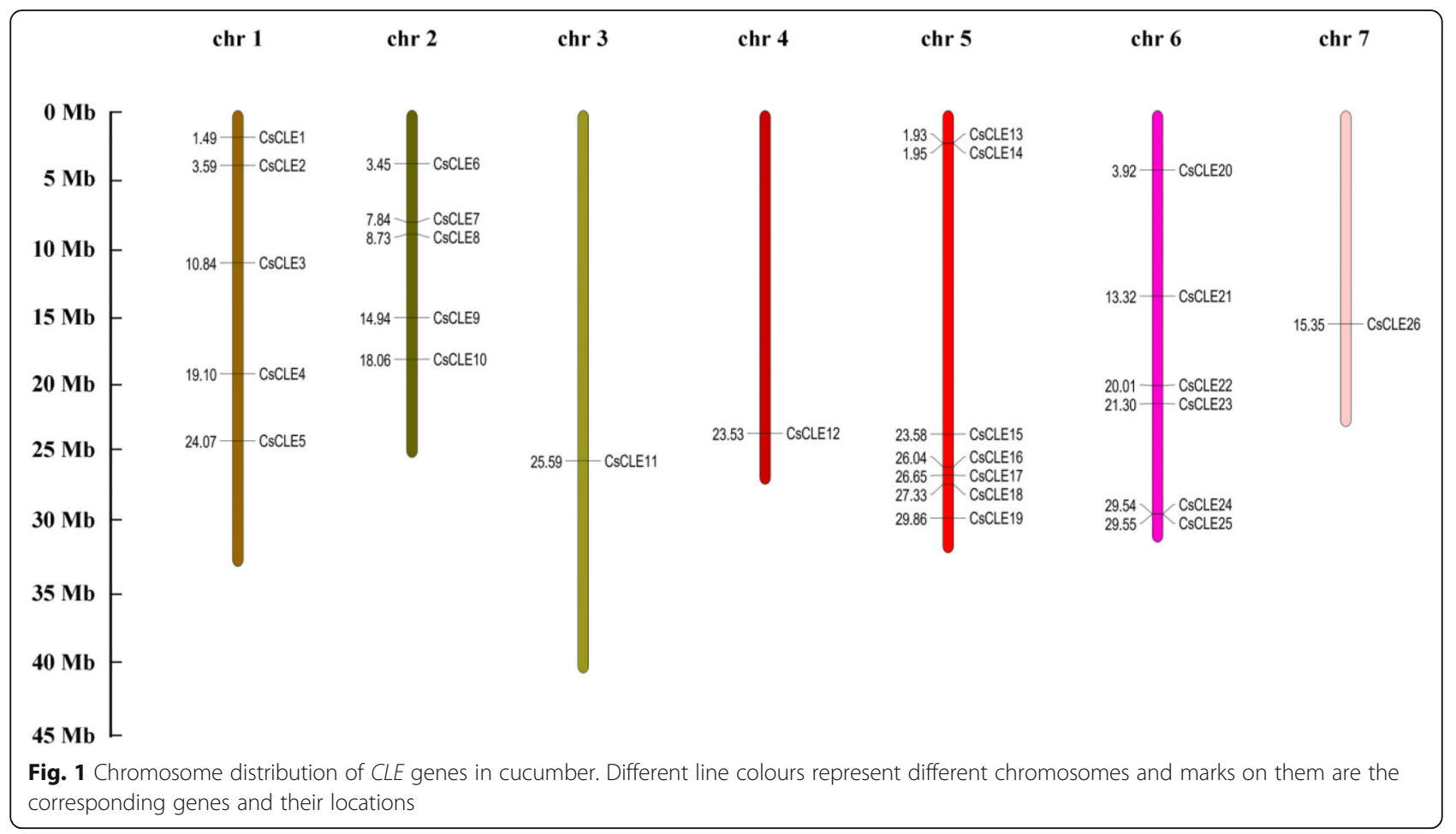

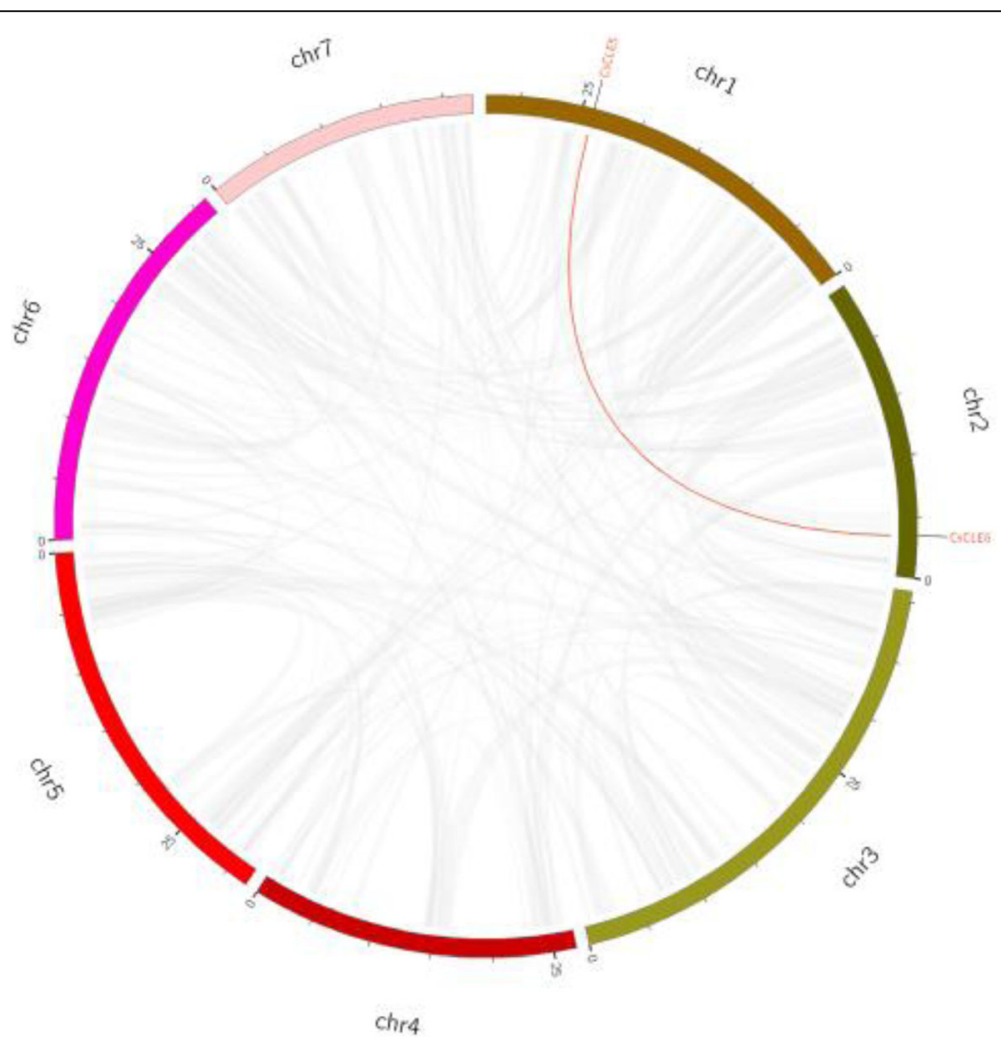

Fig. 2 Distribution of segmental duplication CLE genes CLE5 and CLE6 in the cucumber genome. Two genes of the same segmental duplicated gene pair are labelled in red 


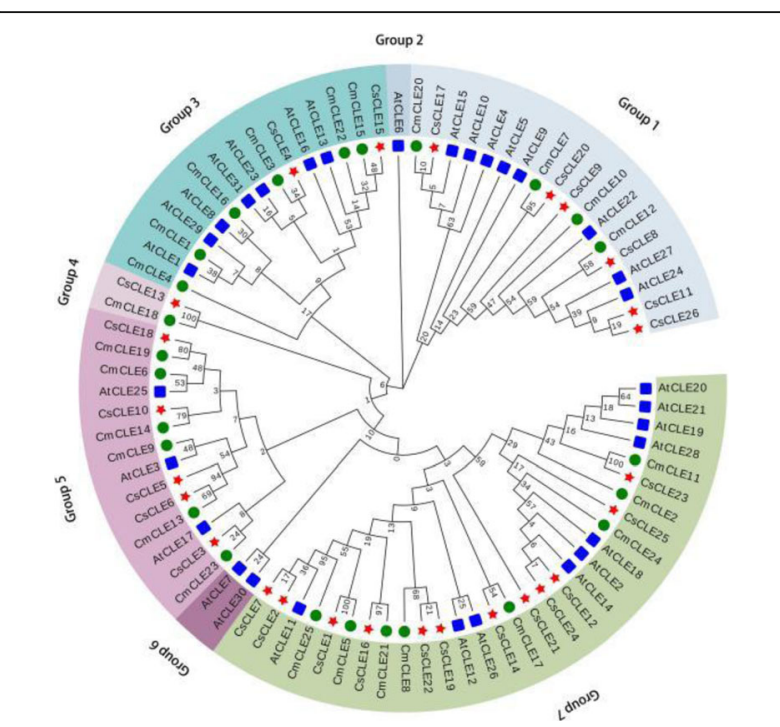

Fig. 3 Phylogenetic analysis of CLE genes from Arabidopsis, cucumber, and melon. The analysis involved 26 cucumber CLE protein sequences, 31 Arabidopsis AtCLE protein sequences, and 25 melon CLE protein sequences. Red stars represent the cucumber CLE proteins; blue squares represent the Arabidopsis CLE proteins; and green circles represent the melon CLE proteins

triple-exon gene. The exon-intron patterns within the same phylogenetic classification group showed similarity. Cucumber gene CLE24 was unique with its discrete coding regions split by 19 introns.

\section{Conserved cucumber CLE protein motifs}

The MEME software was used to explore the conserved domains and motifs of the CLE proteins in cucumber. The motifs were listed from motif 1 to 10 according to the ascending E-value of the alignment (Fig. 4). Almost all cucumber CLE proteins contained motif 1, which represents a typical CLE domain near the C-terminal, except for CsCLE9. Proteins CsCLE5 and CsCLE6 were different at the C-terminal; both contained motif 4 near the C-terminal CLE domain. Protein CsCLE11 contained four tandem located motif 6 and one CLE domain, while CsCLE24 contained two motif 2 in tandem. These results indicated that the sequence characterization and biological function widely differed among cucumber CLE proteins in each branch of the phylogenetic tree. These proteins also possessed other functional domains at the N-terminal or in the middle, while their CLE domain was functional in signal pathways.

\section{Upstream cis-regulatory elements (CREs)}

In the PlantCARE database, the sequence of $1500 \mathrm{bp}$ in the upstream promoter was used to locate the cisregulatory element in the upstream regulatory region. By analyzing the biological functions of CREs in the upstream region of 26 cucumber CLE genes, it can be concluded that most of the components other than those necessary for the normal expression of promoters, such as AT TATA-Box and CAAT-Box, can be divided into the following four categories. 1) The first type of element is hormone response elements, such as ABRE (ABA response element), the TCA-element (salicylic acid response element), the TATC-Box (gibberellin response element), and the TGA-element (auxin response element), among others. These elements were plotted in this experiment (Fig. 5). 2) The second type of element is light-responsive elements, such as ACE, G-box, ATAmotif, LAMP-element, etc. 3). The third type of element is the meristematic expression elements. For example, HD-zip1 (elements related to mesophyll cell differentiation) and TGACG-motif (elements related to meristem development) play an important role in CLE gene regulation of plant meristem maintenance and organogenesis. 4) The fourth type is stress response elements, such as ARE, MBS, TC-rich repeats, LTR, etc., as well as other regulatory factors that play a role in metabolic regulation.

\section{Homologous pairs of cucumber CLE proteins}

To understand the vertical descent from a single ancestral gene and duplication, a comparative analysis was performed to identify the orthologous, co-orthologous, and paralogous gene pairs in Arabidopsis, cucumber, and melon.

The OrthoMCL software identified 24 orthologous, 23 co-orthologous, and 8 paralogous CLE gene pairs among Arabidopsis, cucumber, and melon. This homologous gene pair network was highly consistent with the phylogenetic tree, which is clearly divided into three parts. The orthologous genes between these three species are shown in Fig. 6. Out of 26 cucumber CLE genes, 15 orthologous genes in melon and 7 in Arabidopsis were found.

\section{Selection and divergence time}

In order to investigate the selection mechanisms of CLE genes during evolution, we calculated $\mathrm{Ka}$, Ks, and divergence time of the homologous pair CsCLE24-CsCLE25 (S4 Table). This pair had a Ka of 1.08 and Ks of 0.82, and $\mathrm{Ka} / \mathrm{Ks}$ ratio of 1.31 with a $P$-value of 0.0098 , indicating this gene pair is undergoing a positive selection which led to functional differentiation.

\section{Expression pattern of cucumber CLE genes during development}

We investigated the expression of each CLE gene using published RNA-seq data (S5 Table) for 23 different $\mathrm{cu}-$ cumber tissues during vegetative and reproductive development. The expression level of each gene was normalized using the RPKM method. Ten cucumber CLE genes including CsCLE1, 2, 4, 5, 14, 25, 24, 23, 15, 


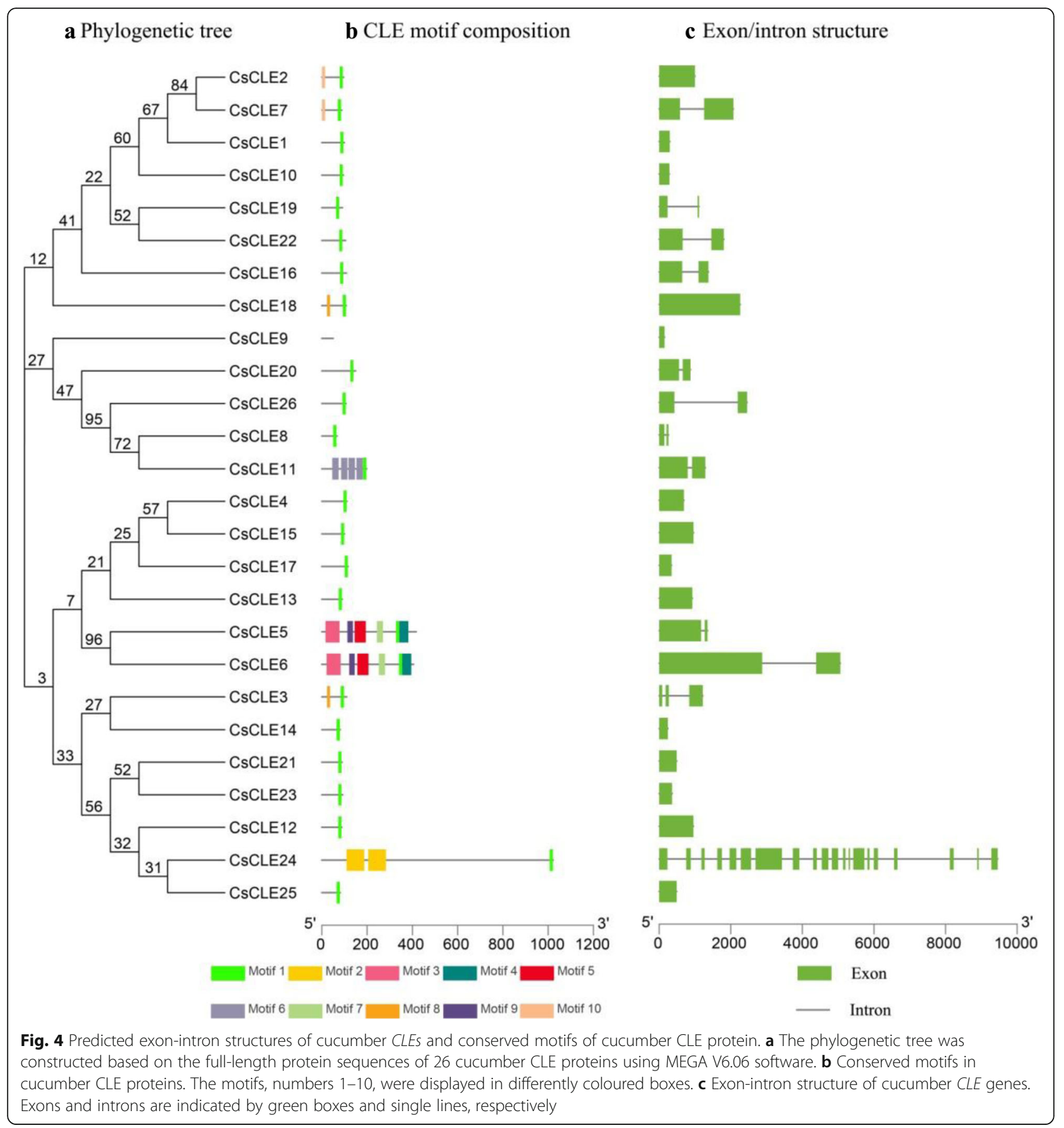

and 17 showed relatively low levels of expression in all 23 samples, showing that they played a negligible role in developmental processes in cucumber. Genes CsCLE9, 10,18 , and 22 showed relatively high levels of expression across multiple samples (Fig. 7a).

Using qPCR, we analyzed the expression of cucumber CLE genes (S6 Table) in different tissues of Chinese long '9930' seedlings. Out of 26 cucumber CLE genes, 24 genes were detected in 21 samples. Genes CLE1 $2,7,8,9,17,18,19$, and 26 were expressed at relatively low levels across all samples, and others were expressed at relatively high levels in at least one sample. Cucumber CLE genes showed relatively high levels of expression in the growing tissues, including point, stem, and flower, and relatively low levels of expression in the root. The expression level of CsCLE4, 6, 11, 14, 21, 23, 24, and 25 was the highest (Fig. 7b). The qPCR results are highly consistent with the former RNA-seq data available in the public database. 


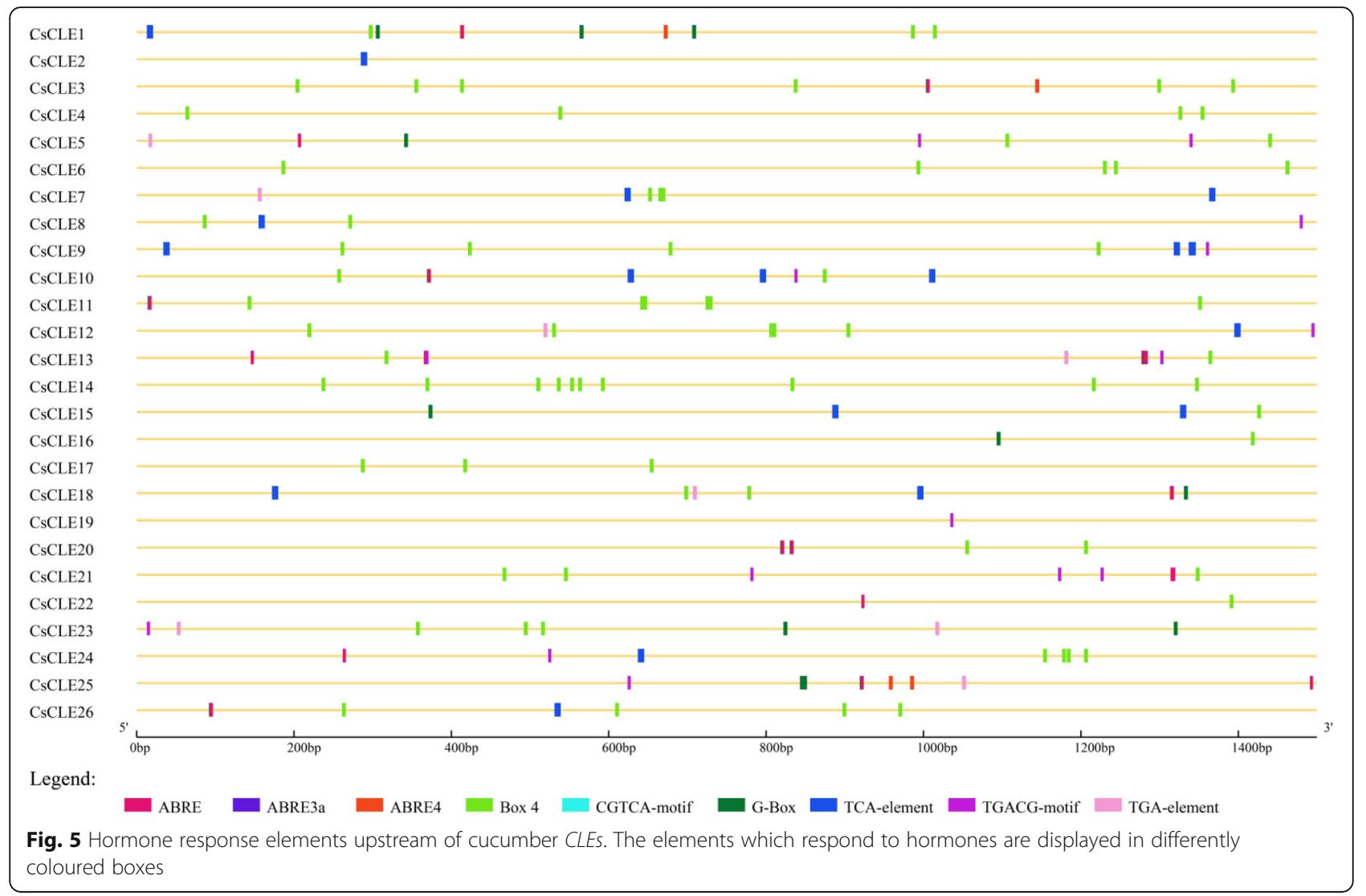

\section{Heterologous overexpression of CsCLV3 gene in Arabidopsis}

The expression vector was successfully constructed by carrying the target gene on PHB plasmid, and then $C s C L V 3$ gene, the representative gene of the CLE family, was overexpressed in Arabidopsis; we refer to these transformed plants as positive strain. The results showed that in the phenotype of positive strain weakness developed at the growing point. Compared with wild type, the growing point diameter of wild type Arabidopsis was about $0.66 \mathrm{~mm}$ (Fig. 8a), and that of CsCLV3 gene overexpression positive strain was about $0.54 \mathrm{~mm}$ (Fig. $8 \mathrm{~b}$ ).
Under the same conditions, the growing point of the positive strain was smaller than that of the wild type.

After transplanting, almost all of the transformed plants in the T1 generation showed the phenomena of obvious weakness of the development of growing point, no bolting, and a decreasing capability of plant growth (Fig. 9). Heritable seeds obtained from T1 plants were extremely few, making functional analysis in subsequent generations unfeasible. Besides, few of the positive strains completed the processes of growth and development. In this study, only two bolted strains showed that either the pod did not develop or the pod was short, and

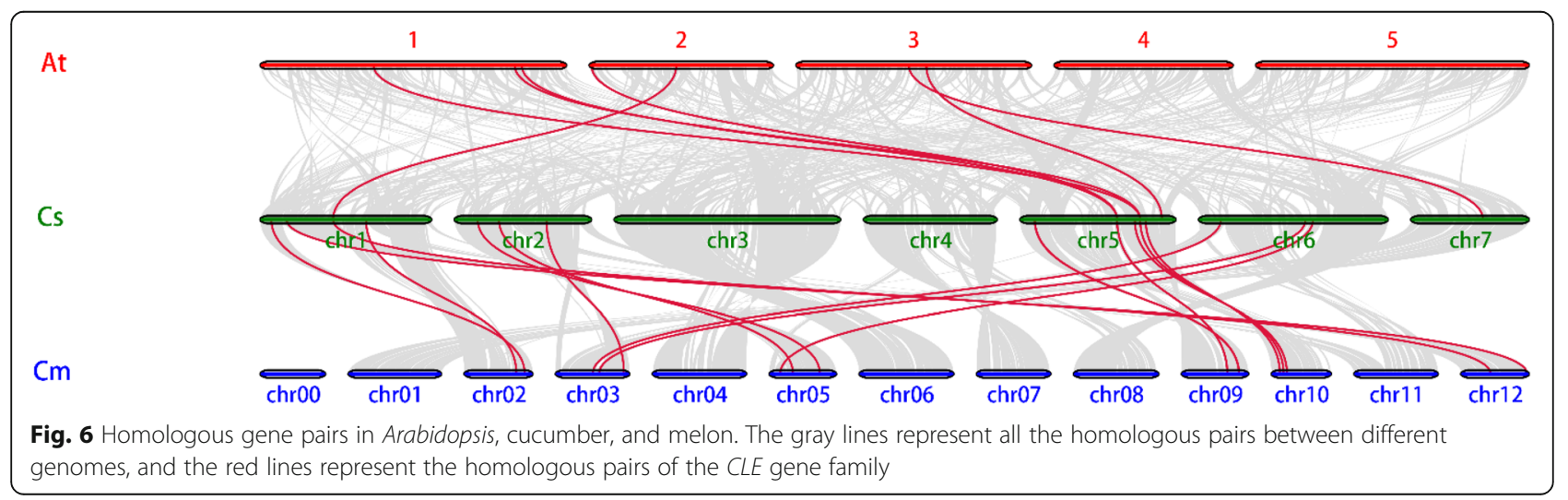



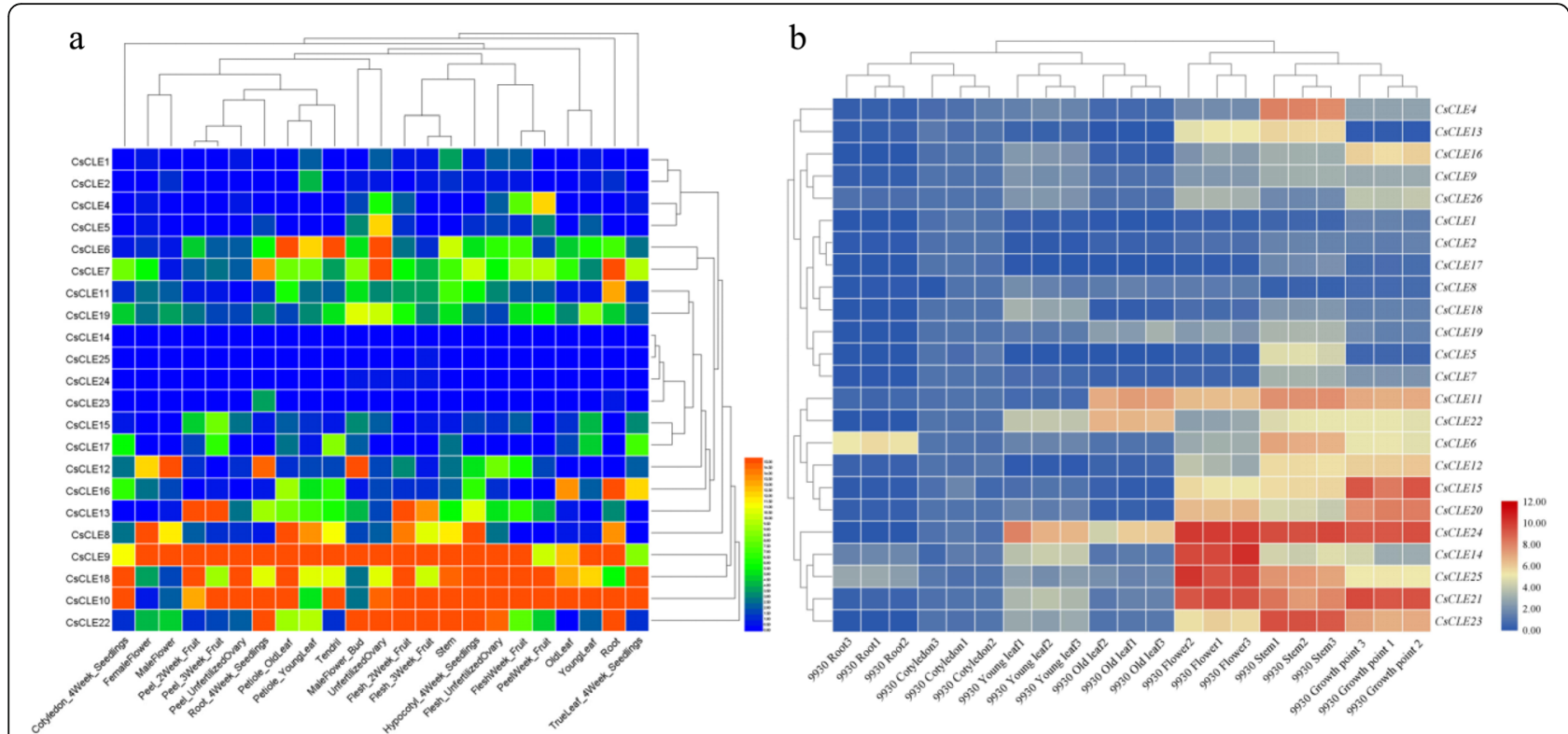

Fig. 7 Expression pattern of cucumber CLE genes. a Heat map representing the expression profile of cucumber CLE genes during different development stages analyzed by RNA-seq data. $\mathbf{b}$ Heat map representing the expression profile of cucumber CLE genes during different developmental stages validated by qPCR in Chinese long '9930'

its development was significantly inferior to that in the wild type (Fig. 10a). Ten transformants were randomly selected for fluorescence quantitative PCR detection (Fig. 10b). The results (S7 Table) showed that the target genes were expressed in all transgenic materials, and the phenotype of No. 15 and No. 8 with lower expression was the weakest, which could bear fruit but not great fruiting ability. At the same time, No.1, 12, and 13, which had high expression levels, had capable phenotypes and high degree of abnormality, and were unable to bolt or fructify. Generally speaking, the expression level of CsCLV3 gene is consistent with its phenotype.
The experimental results proved that cucumber $C L V 3$ genes function in a way essential in controlling the development of growing points and fruits, and plant bolting.

\section{Discussion}

Our study investigated the CLE family genes in cucumber in detail. The spatiotemporal expression characteristics of all family genes in cucumber were also verified quantitatively. Gene CsCLV3, the representative gene of this family, was overexpressed in Arabidopsis. This work provides a new direction and idea for understanding the

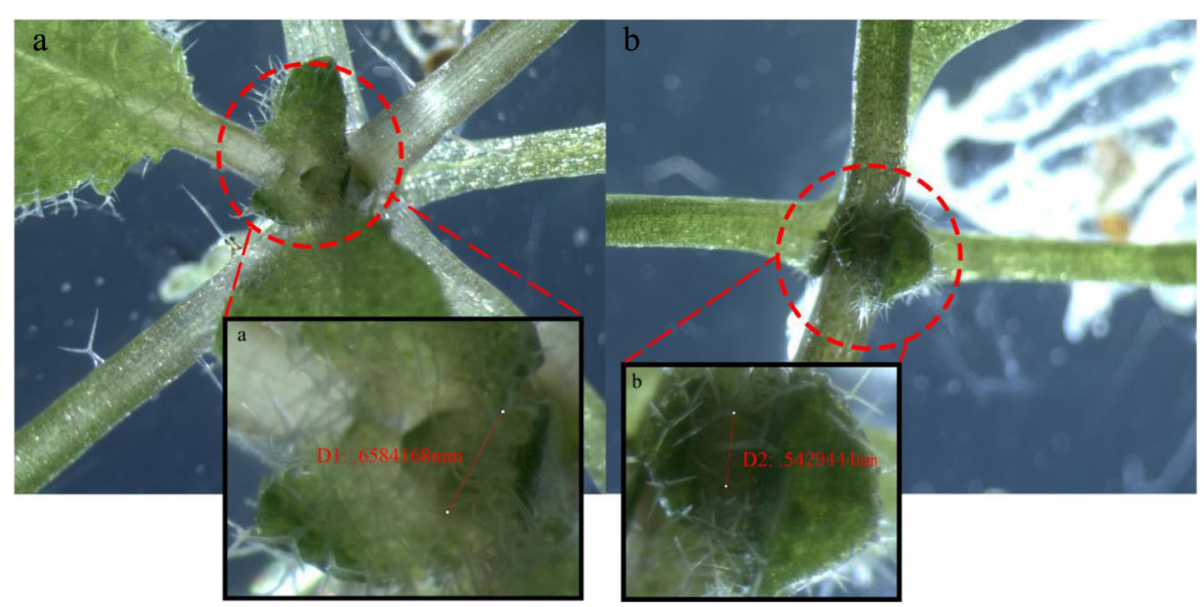

Fig. 8 The growing point of heterologous overexpression of CsCLV3 gene in Arabidopsis. a Growing point of wild type. a Diameter of growing point for wild type is $0.6584168 \mathrm{~mm}$. b Growing point of positive strain. b Diameter of growing point for positive strain is $0.5429444 \mathrm{~mm}$. The diameter of the growing point was measured with IPwin 32 software 


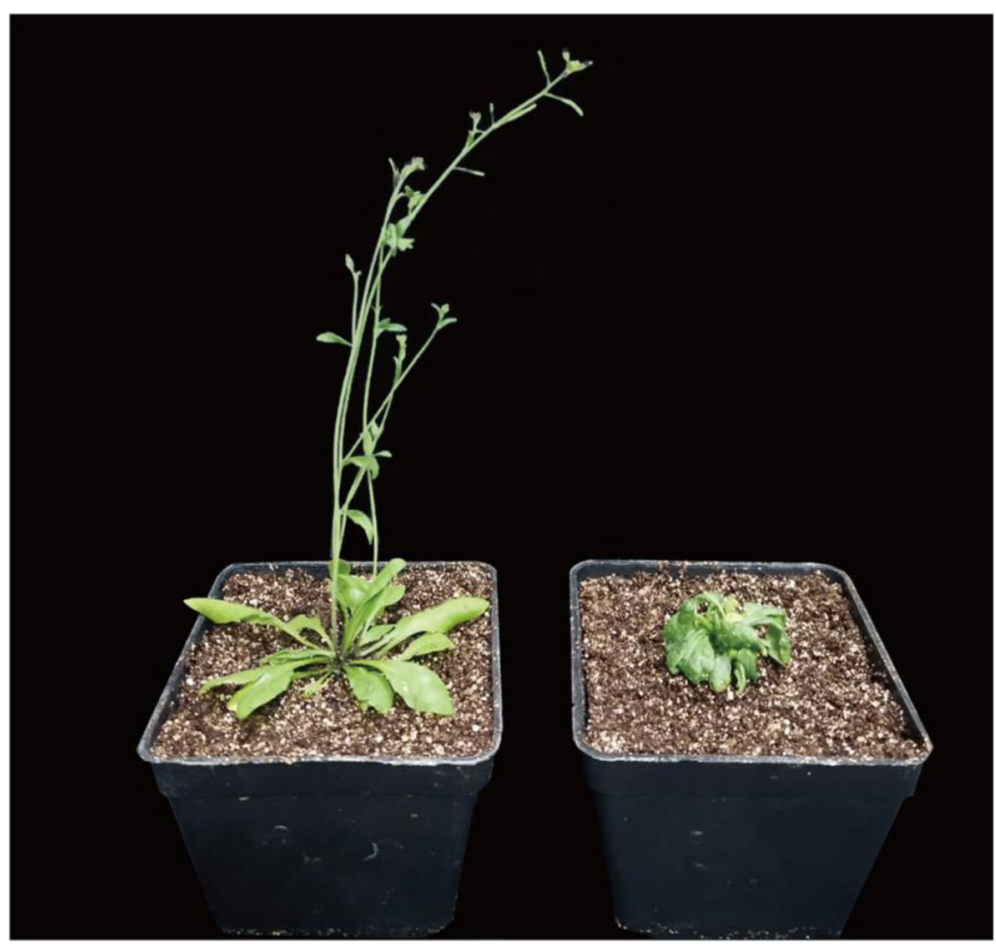

WT(col-0)

4910-13

Fig. 9 Heterologous overexpression of CsCLV3 gene in Arabidopsis. Wild type (WT) strain has normal growth and development cycle, and phenotypic structure of rosette leaves, stems, leaves, pods and so on. The positive strain (4910-13) was the phenomenon of heterologous overexpression of CsCLV3 gene, and it has no stem, leaf, fruit pod or other morphological structures, showing only wrinkled rosette leaves

possible role of cucumber CLE proteins in plant growth and development, especially in fruit setting.

\section{Discovery of the CLE gene family in cucumber}

A newly designed CLE Markov model was used in this study on the basis of which 26 new $C L E$ genes were identified, proving that a CLE domain composed of 14 amino acids at the $\mathrm{C}$-terminal is the conserved motif of the cucumber $C L E$ gene family.

The replacement experiment of CLE domain in CLV3 revealed that the expression of fusion protein retained full physiological activity even after the upstream sequence of the CLE domain was replaced with an unrelated sequence [31]. The elimination experiment of variable domains in CLV3 demonstrated that the function of CLV3 is not significantly influenced by the absence of variable domains [32]. No MCLV3 activity was identified through the artificially synthesized CLE peptides lacking either Arg at the $\mathrm{N}$-terminal or His at the C-terminal in the research of Kondo et al. [33]. In treating synthetic CLV3 peptides, Fiers et al. managed to totally inhibit the mutant phenotype of CLV3 [34]. Previous studies such as the abovementioned prove that the CLE domain is a key domain for the functioning of CLE peptides [35].
In this study, nearly every cucumber CLE protein containing motif 1 represented a typical CLE domain with CsCLE9 as an exception in which no typical CLE domain was detected. In maize, a CLE peptide expressed itself in primordial cells of organs but was manipulated and regulated by functional genes of FASCIATED EAR3 in stem cells, the regulatory function of which was achieved through leucine-rich-repeat receptors [36]. In the initial phase of flower development, stem cell niches are maintained through a negative feedback loop between the homeodomain transcription factor WUSCHEL (WUS) and the ligand-receptor system of CLAVATA3 (CLV3) [37]. The properties of stem cells and the size of FMs (floral meristem) are consequently affected when either of the genes above loses its activity [38]. The expression level published in both RNA-seq data and in the data of Chinese long '9930' indicates a possible high expression of CSCLE9 in tissues with high meristematic activity, which leads us to predict that CsCLE9 may function in the CLAVATA-WUSCHEL feedback signaling between stem cells at the tip of the meristem and the underlying organizing center. This calls for further verification in later studies.

The 26 cucumber CLE family genes identified in this experiment exhibit a high degree of gene expression in 
a

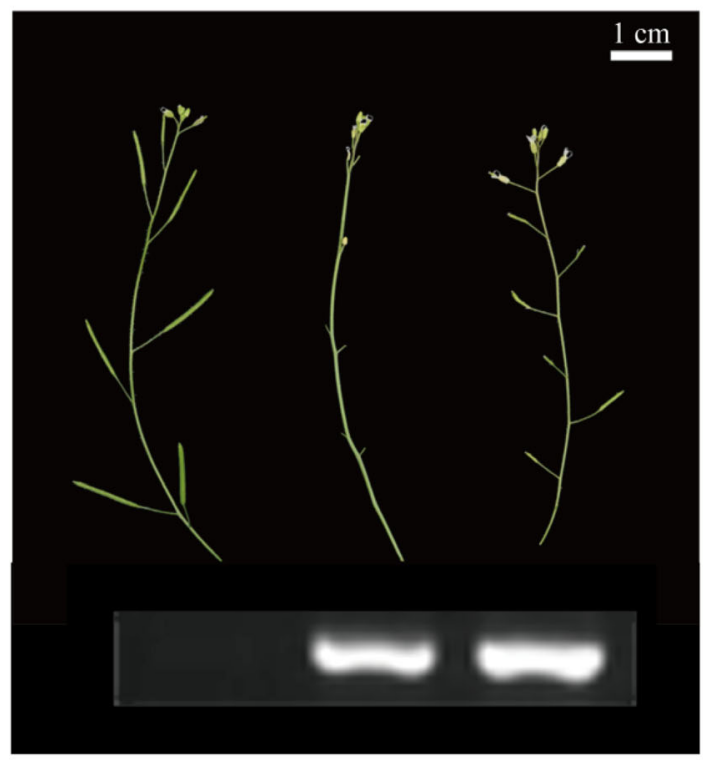

WT(col-0) 4910-15 4910-8 b

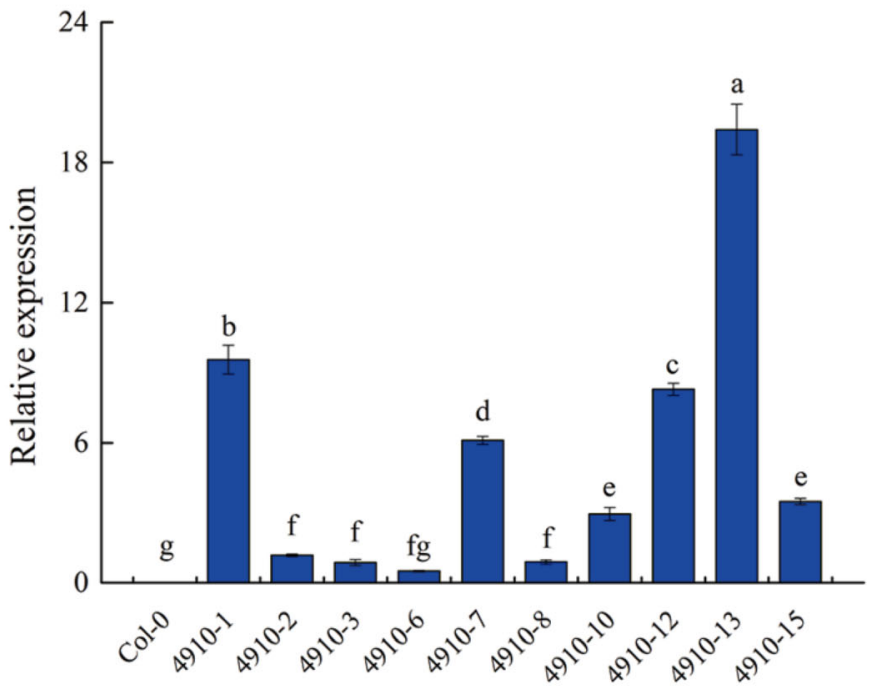

Fig. 10 Pods of lower expression in positive strains. a Pod phenotypes of wild type (col-0) and positive stain (4910-15) could bolt but not bear fruit, while 4910-8 could bolt and bear fruit but internodes were shorter than in WT. Pod phenotypes of Arabidopsis were observed under a Nikon D3300 microscope. The bands shown in the figure are the gene expression corresponding to phenotypes. $\mathbf{b}$ Ten transformants were randomly selected for fluorescence quantitative PCR detection

meristem tissues, vascular bundles, and sites of vigorous growth as is shown in the analysis of public transcriptome data and real-time fluorescence quantitative analysis. However, only one of the 26 cucumber $C L E$ family genes, i.e. CsCLE6, manifests a high degree of expression in plant roots, a finding inconsistent with those of previous studies. The tissue distribution of CLE genes influences their functional specificity to a large extent, as revealed in many tests of CLE protein ectopic expression at stem and root ends, but the location of gene expression is not the sole determinant of the functions of $C L E$ genes [39], as shown in the cases of CsCLE6 and CsCLE9 in the current study. The CLE polypeptide family is a group of secreted peptide hormones that function among cells and play an essential role in the formation of stems, roots, vascular tissues, and pod nodules of plants $[40,41]$. Numerous studies have demonstrated that CLE polypeptides are a significant kind of regulatory factors for keeping the balance between proliferation and differentiation of stem cells [34, 42].

\section{Phylogenetic analysis and evolution of cucumber CLE genes}

According to the types of phylogenetic relationships, $C L E$ s from three different plant species were divided in this research into seven groups within each group containing at least one Arabidopsis sequence. This provides necessary evidence for the identification of the conservation of CLEs in different plants. However, CLE genes do not distribute uniformly in the three different species. In cucumber, there are 12 CLE genes and the highest number of Arabidopsis CLE genes is found in Group 7, in which the largest number of $C s C L E$ genes was identified. However, in neither Group 2 nor Group 6 were cucumber- or melon CLE genes found. Such difference may imply certain physiological significance. Rapid adaptive evolution is more likely to happen in groups with more genetic members than in groups with fewer genetic members, as hypothesized in a previous study [43]. In terms of the physiological functions of CLE peptides [44], the Arabidopsis CLE genes in Group 7 are classified as class $\mathrm{A}$ genes which function through the inhibition of the proliferation and division of apical meristem stem cells and root meristem stem cells. Cucumber and melon CLE genes that are classified into the same group can both be analyzed with reference to similar functions, the finding of which lays a foundation for future researches on the gene functions of CLE in Cucurbitaceae.

As shown in Fig. 11, we compared the evolutionary relationship and the species relationship and obtained the relationship among orthologous genes. It can be seen that the positions of orthologous genes in the phylogenetic tree are quite close, which indicates that the evolutionary relationship of CLE family genes among the 


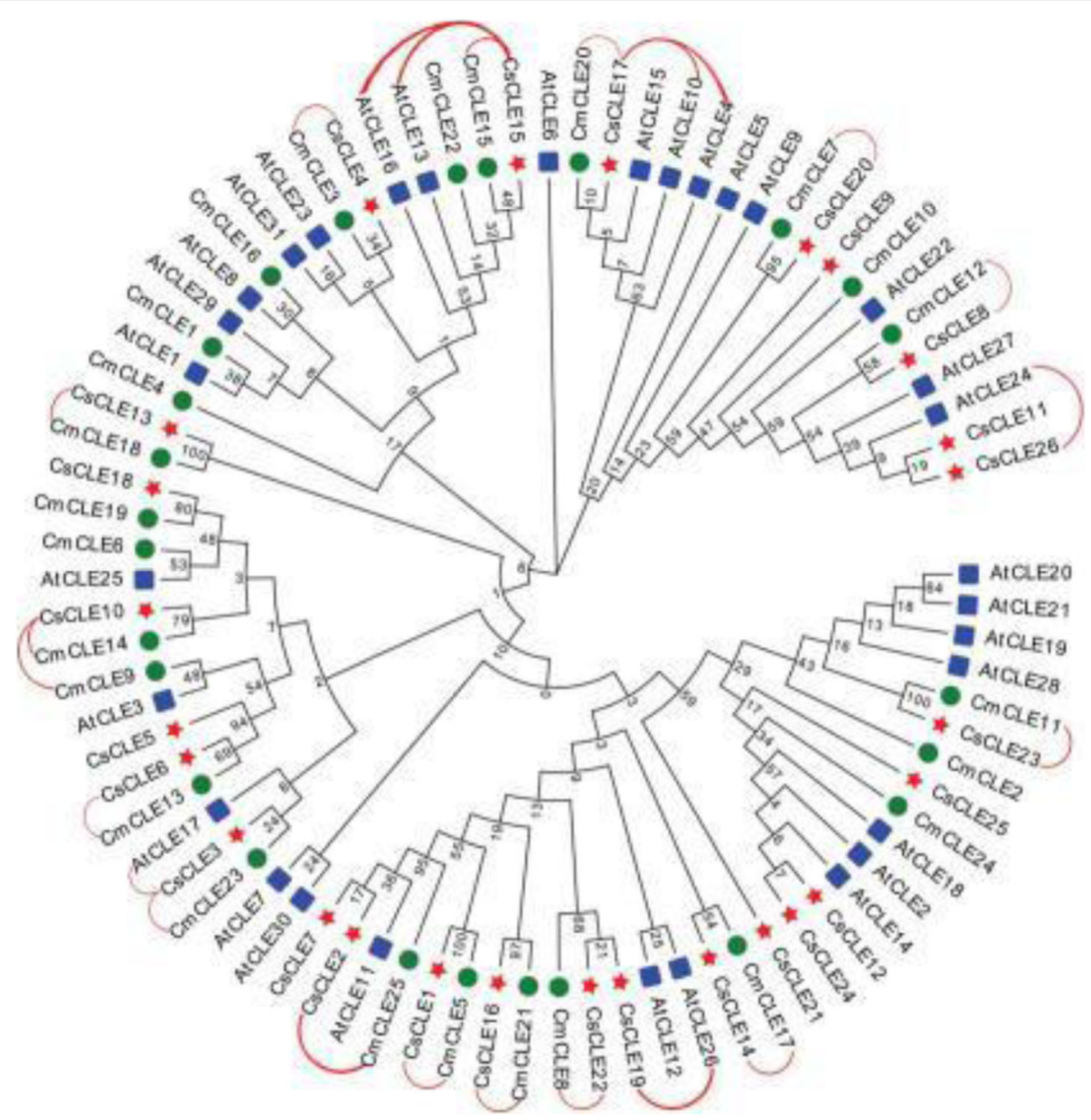

Fig. 11 Comparison between the evolutionary and the species relationship, and the relationship among orthologous genes in Arabidopsis, melon and cucumber. The figure is the result of representing the homologous pairs in Fig. 6 in Fig. 3, and the red lines represent the homologous pairs of the CLE gene family

three species is relatively close. Based on this, we can infer the functions of the related genes of cucumber and melon that are orthologous to those in Arabidopsis, as the latter has been studied in a relatively thorough manner. If CsCLE19 is orthologous to AtCLE26, it can be inferred that its function is similar to AtCLE26; AtCLE26 can inhibit the division of stem cells in the apical meristem and root meristem but cannot inhibit the division and differentiation of the procambium nor can it inhibit the differentiation of primary xylem vessels. This predicted function is different from the predictions of several other orthologous gene pairs, namely, CsCLE3/CmCLE23/AtCLE17, CsCLE15/CmCLE15/AtCLE13/AtCLE16 and CsCLE17/ CmCLE20/AtCLE10, which can inhibit the stem cells of apical meristem and root meristem. This difference can also be verified by measuring the gene expression. Gene CsCLE19 exhibited a significantly different temporal and spatial expression pattern from CsCLE15 and CsCLE17. In terms of the expression in the non- stem apex and root tip meristems, CsCLE19 also had a higher expression.

Considering that a homologous gene of CsCLE26 was found in Arabidopsis but not in melon, it is assumed that CsCLE26 was retained in ancient cucurbits but was eliminated in melon in the process of evolution.

\section{Putative functions of CSCLE genes in hormone response and plant growth}

The identification of cis-regulatory elements such as ABRE, AuxRR-core, and TCA-elements in response to hormones in 26 CsCLE genes indicated a dynamic mutual interaction between CsCLE polypeptides and hormones of other kinds. The frequent occurrence of cisregulatory elements in either ABRE or ABA-dependent response uncovers the function of CLE genes in $\mathrm{ABA}$ dependent reactions under stringent conditions [45]. The gene name of $C L E$ is a compound derived from the name of $C L V 3$ genes of Arabidopsis and that of Embryo Surrounding Region (ESR) genes of maize [46]. All the 
CLEs identified up to date share quite similar protein structures [47], usually with a short secretory signal peptide at the $\mathrm{N}$-terminal, a long variable domain in between, and a conserved CLE domain at the C-terminal of the protein. Such conserved CLE domain is generally composed of 12-13 amino acid residues and is crucial for the functional execution of CLE proteins [48, 49]. One of the main features of $C L E$ genes is their highly conserved structural domain at the C-terminals. Moreover, it is impossible to identify those CLE members that are expressed at relatively low levels using high-throughput sequencing. At the early stage of gene studies, the genome-wide identification of CLE genes in plants was conducted using BLASTP. Hidden Markov models and position-specific iterative BLAST method were employed by Oelkers et al. and more than 100 new CLE members were identified in 19 different species [46].

Essential elements such as the CAT-box and others that are crucial for $C L E$ gene regulation in the process of maintenance of plant meristem and organogenesis, were definitely detected. Besides the analysis of the effect of overexpression of Raphanus sativus CLEs encoded with CLE peptides on secondary root structure in Raphanus sativus, Gancheva et al. [50] investigated the effect of synthetic CLE peptides treatment on Raphanus sativus and $R$. raphanistrum plants. For plants with a changing quantity of CLE peptides in roots resulting from either $C L E$ overexpression or exogenous CLE treatment, the development of tissues in store roots alters accordingly. Additionally, a group of essential elements exist in numerous light regulation genes and groups of essential elements relate to environmental stimuli include responses to biotic and abiotic stresses. The existence of all four kinds of essential elements discussed above unveils the possible functions of $C L E$ genes in corresponding responsive mechanisms.

\section{Cucumber CLV3 genes act as critical regulatory in cucumber bolting and fruit bearing}

Overexpression of CLE genes often shows a common dwarf and short-root phenotype [51], but in this study the overexpression of $C s C L V 3$ gene showed internode shortening but no obvious dwarfism in total stem length. Brand et al. [34] used transgenic plants overexpressing $C L V 3$ to show that the shoot meristem arrests after initiation of the first leaves (arrow), and the phenotypic results were similar to those in this study. Stamens and carpels are missing in the flower of the transgenic, at the same time, they also inspected the phenotype of clv3 mutants, and the mutant flower showed organ number increased particularly carpel. $C L V 3$ is a specific regulator of shoot and floral meristem development [52]. In Brassica rapa, it was proven that the multilocular mutant contained more stamens and carpels in the functional characterization of the multilocular silique gene $B r C L V 3$, and most of its siliques had 4 locules with a shorter, rounder and thicker shape and extra gynoecium inside [53]. Knockout of rapeseed homologues of CLV3 using the CRISPR/Cas9 system, and the double mutation of $B n C L V 3$ produced more leaves and multilocular siliques with a significantly higher number of seeds per silique and a higher seed weight than the wild-type and single mutant plants [54]. The gene of CsCLV3, a homolog of the Arabidopsis gene CLV3. Fine genetic mapping in F2 and RIL populations and association analysis in natural populations confirmed $C s C L V 3$ as the candidate gene for $\mathrm{Cn}$ (carpel gene) [55]. However, as for the paeonia rockii carpel, recent genetic studies [56] have shown that the phenotypic carpel is the complex of gene regulation networks. There are multiple candidate genes, and we are also actively verifying CLV3 as a candidate gene for cucumber carpel numbers. It is believed that the specific relationship between the CSCLV3 gene and cucumber carpel number phenotype will be clearly depicted in the near future.

The phenotype of weak growth point and loss of bolting and fruit bearing ability was obvious in the T1 generation. Our experiment of heterologous overexpression of representative CLV3 gene in Arabidopsis revealed that more than half the number of transformed lightdemanding plants in the T1 generation manifested responses such as stunted growth points, lack of bolting, plant shrinkage, etc., and some bolted lines grew to be short and stunted strains that were even significantly less developed compared to the wild-type strains. In contrast, the double mutation of $B n C L V 3$ produced more leaves and multilocular siliques with a significantly higher number of seeds per contributing to increased seed production. Results above demonstrate that $C s C L V 3$ gene function as a regulatory factor, most likely controlling plant development at different growing points and the processes of bolting and fruit bearing.

\section{Conclusions}

Twenty-six CLE family genes were identified in the genome of Chinese long '9930' cucumber. Almost all of the family members contained motif 1 , a typical CLE domain, at the C-terminal. Analysis of CREs in the upstream promoter region of the genes predicted that this gene family might be related to hormone response in $\mathrm{cu}$ cumber growth and development. The results of interspecies evolutionary analysis showed that the genes of the $C L E$ family in cucumber were closely related to the model plants Arabidopsis and congener melon, with cucumber sharing seven orthologous CLE genes with Arabidopsis and 15 with melon. The analysis of a pair of orthologous genes in cucumber showed that as a part of the evolutionary process, CLE genes are undergoing a 
positive selection process which leads to functional differentiation. The family representative gene $C s C L V 3$ acts as a significant factor in the process of the development of growth points and functions in the growth of plant bolting and pod of those plants of positive transformation in which the expression was relatively low.

\section{Methods}

\section{Identification of cucumber CLE genes}

The genome, gene sequences, and corresponding protein sequences of cucumber were downloaded from cucumber genome database (CuGenDB,http:// cucurbitgenomics.org/). The Markov models of two identical domains for the $C L E$ genes were constructed using known Arabidopsis CLE proteins. All cucumber proteins were aligned with these Markov models using the HMMER program (http://www.hmmer.org/) with a domain cut-off E-value of $\mathrm{e}^{-3}$. The CLE genes located at a distance of $10 \mathrm{~kb}$ apart on the same chromosome or scaffold were considered as tandemly duplicated genes.

The genome and annotated proteins of the model plant Arabidopsis were downloaded from TAIR database (https://www.arabidopsis.org/) [57]. The genome and annotated proteins of Cucumis melo were downloaded from $\mathrm{CuGenDB}$ database. Candidate proteins with only the CLE domains were eliminated manually. The Protparam (http://web.expasy.org/protparam/) [58] was employed to analyze the physical and chemical characteristics, including the molecular weight, theoretical isoelectric point (pI), atomic composition formula, instability index, aliphatic index, and grand average of hydropathicity (GRAVY), of the CLE proteins in these analyzed species.

\section{Phylogenetic analysis}

The putative CLEs were determined by searching the melon genome database with HMM (Hidden Markov Model) profiles constructed using CLE sequences from Arabidopsis as queries. All the putative CLEs were further subjected to Pfam and SMART analyses to identify their conserved domains and signature sequences. Protein sequences from multiple species were used for a phylogenetic analysis in planta. Pairwise alignment and multiple alignment were performed using the ClustalX2 program with Gonnet protein weight matrix [59], and a maximum likelihood phylogenetic tree was built with the MEGA program (v6.06) using the conserved protein sequence of the cucumber $C L E$ genes. Uniform rates and homogeneous lineages were adopted, and the partial deletion with a site coverage cutoff of $70 \%$ was used for gaps/missing data treatment. The frequency of each divergent branch higher than $50 \%$ was displayed. The figure was processed using the Adobe Illustrator software.

\section{Gene structure and motif analysis}

The gene structure was analyzed using Gene Structure Display Server tool (http://gsds.cbi.pku.edu.cn/, v2.0) [60]. The MEME software (http://meme.nbcr.net/ meme/, v4.12.0) was used to search for motifs (10 to $100 \mathrm{bp}$ long) in the proteins [61]. Only widely distributed motifs that occurred in at least three protein sequences were retained. These motifs are represented in two separate figures, in accordance with the phylogenetic trees. The top ten motifs (with the lowest E-values) were reported, and statistically significant (lower E-value) motifs came first in the display.

\section{Upstream Cis-regulatory elements (CREs)}

A 1500 bp fragment located before the initiation codon ATG of CLE gene family was captured use perl script from the cucumber genome sequence, and the online website PlantCARE (http://bioinformatics.psb.ugent.be/ webtools/plantcare/html/) was used to analyze CREs of them. The figure was drawn using the online software GSDS (http://gsds.cbi.pku.edu.cn/).

\section{Identification of orthologous and paralogous genes}

OrthoMCL software (v2.0.3) [62] was employed to search for orthologous, co-orthologous, and paralogous genes in Arabidopsis, cucumber, and melon using entire $C L E$ protein sequences. An E-value cut-off of an allagainst-all BLASTP alignment process was set at $1 \mathrm{e}^{-5}$, and the alignment with a match cut-off value lower than 50 was eliminated. Nonsynonymous (amino acidreplacing, Ka) and synonymous (Ks) substitution rates among protein-coding sequences were used to reveal the DNA sequence evolution. The $\mathrm{Ka} / \mathrm{Ks}$ ratio $(\mathrm{Ka} / \mathrm{Ks})$ was used to estimate the selective strength for DNA sequence evolution; $\mathrm{Ka} / \mathrm{Ks}>1$ indicates positive selection, $\mathrm{Ka} / \mathrm{Ks}<1$ indicates purifying (negative) selection, and $\mathrm{Ka} / \mathrm{Ks}$ close to 1 indicates neutral mutation [63]. The ParaAT software (http://cbb.big.ac.cn/software) is capable of constructing multiple protein-coding DNA alignments in parallel for a large number of homologous genes [64]. To evaluate the divergence of duplicated cucumber CLE genes, synonymous rate (Ks), nonsynonymous rate $(\mathrm{Ka})$, and evolutionary constraint $(\mathrm{Ka} / \mathrm{Ks})$ between paralogous pairs of genes were calculated with the KaKs_calculator tool and paraAT software using the method developed by Nei and Gojobori (http://cbb.big. ac.cn/software). The divergence time was calculated for the homologous pair using the formula $\mathrm{T}=\mathrm{Ks} / 2 \mathrm{R}$, where $\mathrm{R}$ is the rate of divergence for nuclear genes from plants, and is $\mathrm{R}=1.5 \times 10^{-8}$ synonymous substitutions per site per year for dicotyledonous plants [65]. The selected homologous pairs of Arabidopsis, cucumber, and melon were gathered and displayed using Cytoscape software (http://www.cytoscape.org, v2.8.3) [66]. 
Tissue-specific gene expression analysis of CsCLEs

The gene expression data of cucumber CLE genes were gathered from CuGenDB (http://cucurbitgenomics.org/ rnaseq/cu/17) (NCBI accession: PRJNA312872) [67]. The RNA-seq data from Cotyledon_4Week_Seedlings, FemaleFlower, Flesh_2Week_Fruit, Flesh_3Week_Fruit, Flesh_UnfertilizedOvary, FleshWeek_Fruit, Hypocotyl_ 4Week_Seedlings, MaleFlower_Bud, MaleFlower, OldLeaf, Peel_2Week_Fruit, Peel_3Week_Fruit, Peel_UnfertilizedOvary, PeelWeek_Fruit, Petiole_OldLeaf, Petiole_ YoungLeaf, Root_4Week_Seedlings, Root Stem,Tendril, TrueLeaf_4Week_Seedlings, UnfertilizedOvary and YoungLeaf of cucumber cultivar Chinese long '9930' were used. The TopHat program (https://ccb.jhu.edu/ software/tophat/ index.shtml, v2.1.0) was used to map the reads to cucumber genome; expression profile of all the cucumber genes was then obtained with the FPKM (Fragments Per Kilobase of exon per million fragments Mapped) value using Cufflinks software (http://coletrapnell-lab.github.io/cufflinks, v2.2.1) under the guidance of annotated gene models with a GFF file. The cucumber $C L E$ gene expression profile from each sample was analyzed using the HemI program. The gene expression profile in each sample was standardized using RPKM (reads per kilobase per million reads) method. The expression profile of cucumber CLE genes from each sample was clustered and the heatmap was drawn using the HemI program (http://hemi.biocuckoo.org/). After normalization using the default linear method, expression data were clustered using hierarchical average linkage algorithm and Euclidean distance similarity metric algorithm in both the horizontal axis and the vertical axis.

\section{Tissue-specific gene expression in the cucumber line Chinese long '9930'}

The cucumber line Chinese long '9930' was used as the plant material to explore CsCLE expression differentiation in different tissues. Seeds were soaked for $15 \mathrm{~min}$ in water at $55^{\circ} \mathrm{C}$ and placed overnight at $28{ }^{\circ} \mathrm{C}$ for germination. The seedlings were allowed to grow in a controlled-environment growth chamber programmed for a photoperiod of $16 / 8 \mathrm{~h}$ (light/dark) and an air temperature of $28 / 18^{\circ} \mathrm{C}$ (day/night). At the four-leaf stage, roots, stems, mature leaves, young leaves, growth points, and cotyledons were harvested and snap-frozen in liquid nitrogen. At the flowering stage, flowers were harvested and snap-frozen before storage at $-80^{\circ} \mathrm{C}$ for further analysis.

An RNA kit (Takara, Kyoto, Japan) was used to extract total RNA from the isolated plant tissues according to the manufacturer's instructions. The Prime Script RT reagent kit (Takara, Kyoto, Japan) was used to reverse transcribe RNA into cDNA. The Primer 5.0 software was used to design specific primers according to the CLE gene sequences. Cucumber actin gene (CuGenDB name: Csa6G484600) was used as an internal control to normalize the expression level of the target genes among different samples. Three biological and three technical replicates were used. Each reaction was performed in a $20 \mu \mathrm{L}$ reaction mixture containing diluted cDNA sample as the template, SYBR Pre-mix Ex Taq (2×) (Takara), and gene-specific primers. Quantitative real-time PCR (qPCR) was performed using a CFX96 Single color RealTime PCR Detection System (BioRad, Hercules, CA, USA) with the following cycling profile: $95^{\circ} \mathrm{C}$ for $20 \mathrm{~s}$ followed by 40 cycles at $95^{\circ} \mathrm{C}$ for $3 \mathrm{~s}$ and $60^{\circ} \mathrm{C}$ for $30 \mathrm{~s}$; and a melting curve $\left(61\right.$ cycles at $65^{\circ} \mathrm{C}$ for $\left.10 \mathrm{~s}\right)$ was generated to check the specificity of the reaction. The comparative $\mathrm{Ct}$ value method was employed to analyze the relative gene expression level. The RNA level was expressed relative to the actin gene expression level following $2^{-\triangle \Delta C T}$ method. The $C L E$ gene expression cluster was analyzed via the TBTOOLS software [68].

\section{Heterologous overexpression of CsCLV3 gene in Arabidopsis}

The gene name of CLE is composed of the CLV3 gene of Arabidopsis and the Emeryo Surrounding Region (ESR) gene of maize. In this experiment, the representative gene $C s C L V 3$ of the $C L E$ family was heterologously overexpressed in Arabidopsis to explore the possible gene function of CsCLV3. Variety 'GY14' was employed as test material to clone $C s C L V 3$ gene, and its cDNA was obtained by the same method as for that of Chinese long ' 9930 ' as mentioned above. The reference sequence was obtained from the cucurbit genomics database (CuGenDB, http://cucurbitgenomics.org/feature/gene/ CsGy1G014910). The primers were designed by SnapGene, and the target gene was amplified. The gene cloning product and expression vector PHB were transformed into E. coli DH5 $\alpha$ competent cells respectively, digested by double digestion method (the digestion sites were Hind III and $\mathrm{Xba}$ I), ligated by T4DNA ligase, cultured overnight at $37^{\circ} \mathrm{C}$, and the positive clones were screened by bacterial PCR. The expression vector with the target gene correctly loaded as a result of sequencing was obtained.

Transgenic plants of Arabidopsis were obtained by floral dip. The connected PHB expression vector was transferred into the competent cells of Agrobacterium tumefaciens GV3101 by freeze-thaw method. The bacterial suspension was prepared by the identified A. tumefaciens monoclonal using transformation buffer, and was used to infect plants of Arabidopsis when the OD value was about 1.0. Water was poured on the flowering plants 1 day in advance, and all inflorescences were inverted into the bacterial liquid suspended in advance by the 
transformation buffer for about $30 \mathrm{~s}$; the transformation as repeated once after 7 days. After growing for 2-3 weeks, less nutrient solution was poured to accelerate aging, and mature seeds were harvested and dried for later determinations. Half-strength MS (murashige and skoog medium) ( $\mathrm{pH}$ 5.8) solid medium with $30 \mu \mathrm{g} \mathrm{mL}^{-1}$ hygromycin was used to screen positive seedlings of transformed plants. After disinfection, the seeds were sown on the screening medium, placed at $4{ }^{\circ} \mathrm{C}$ for $48 \mathrm{~h}$, and then transferred to an incubator. The conditions for germination and growth were $25^{\circ} \mathrm{C}, 16 \mathrm{~h} / 8 \mathrm{~h}$ (light/ dark), 30,000 lx light intensity, and 60\% relative humidity. Positive strains could be distinguished after about 2 weeks, when they were transplanted and followed up.

\section{Supplementary Information}

The online version contains supplementary material available at https://doi. org/10.1186/s12870-021-02900-2.

Additional file 1: S1 Table. Location and sequences of cucumber CLE genes. S2 Table. Location and sequences of Arabidopsis CLE genes. S3 Table. Location and sequences of melon CLE genes. S4 Table. Ka, Ks, and divergence time of the homologous pair CSCLE24-CSCLE25. S5 Table. RPKM of cucumber CLE genes during different developmental stages. S6 Table. Expression of cucumber CLE genes during different tissue in Chinese long '9930'. S7 Table. Expression of heterologous overexpression of CsCLV3 gene in Arabidopsis.

\section{Acknowledgements}

We thank Professor Yanxi Pei, Professor Jin Xu, and Professor Xiuping Kang who gave valuable advice on experiment design and thesis writing. I would like to thank the 'Collaborative Innovation Center for Improving the Quality and Efficiency of Greenhouse Vegetable in Shanxi Province' for providing experimental conditions such as instruments and equipment for our study. I hope you can approve the addition to express my gratitude.

\section{Authors' contributions}

Nannan Qin conceived and designed the experiments, analyzed the data, wrote the manuscript, prepared the figures and tables, and reviewed the manuscript drafts. Guoming Xing and Sen Li contributed reagents/materials/ analysis tools and revised the manuscript drafts. Yang Gao analyzed the data. Xiaojing Cheng, Jiang Wu, Yang Yang, and Jinyao Wang cultivated the experimental material. The author(s) read and approved the final manuscript.

\section{Funding}

This project was funded by National Natural Science Foundation of China (NSFC) (no. 31601754) and the Nature Science Foundation of Shanxi Province for Young Scholar (no. 201701D11111204).

\section{Availability of data and materials}

The datasets supporting the conclusions of this article are available in the Treebase repository, [unique persistent identifier and hyperlink to datasets in http://purl.org/phylo/treebase/phylows/study/TB2:S27518?x-access-code= a142631fde4f4d2f9f68ba859afcbc38\&format=html].

\section{Declarations}

\section{Competing interests}

The authors declare no competing interests.
Received: 30 December 2020 Accepted: 18 February 2021

Published online: 19 March 2021

\section{References}

1. Pearce G, Strydom D, Johnson S, et al. A polypeptide from tomato leaves induces wound-inducible proteinase inhibitor proteins. Science. 1991; 253(5022):895-7.

2. Huffaker A, Pearce G, Ryan CA. An endogenous peptide signal in Arabidopsis activates components of the innate immune response. Proc Natl Acad Sci U S A. 2006;103(26):10098-103.

3. Nakaminami $\mathrm{K}$, Okamoto $\mathrm{M}$, Hiquchi-Takeuchi $\mathrm{M}$, et al. AtPep3 is a hormone-like peptide that plays a role in the salinity stress tolerance of plants. Proc Natl Acad Sci U S A. 2018;115(22):5810-5.

4. Zhou Y, Liu X, Engstrom EM, et al. Control of plant stem cell function by conserved interacting transcriptional regulators. Nature. 2015;517(7534):37780.

5. Matsuzaki Y, Ogawa-Ohnishi M, Mori A, et al. Secreted peptide signals required for maintenance of root stem cell niche in Arabidopsis. Science. 2010;329(5995):1065-7.

6. Mohd-Radzman NA, Laffont C, Ivanovici A, et al. Different pathways act downstream of the peptide receptor CRA2 to regulate lateral root and nodule development. Plant Physiol. 2016;171(4):2536-48.

7. Rodriguez-Villalon A, Gujas B, Van Wijk R, et al. Primary root protophloem differentiation requires balanced phosphatidylinositol-4, 5-biphosphate levels and systemically affects root branching. Development. 2015;142(8): 1437-46.

8. Suk $L$, Marketa $H$, Michal $M$, et al. Competitive binding of antagonistic peptides fine-tunes stomatal patterning. Nature. 2015;522(7557):439-43.

9. Wang $T$, Liang $L, X u e ~ Y$, et al. A receptor heteromer mediates the male perception of female attractants in plants. Nature. 2016;531(7593):241-4.

10. Wang J, Li H, Han Z, et al. Allosteric receptor activation by the plant peptide hormone phytosulfokine. Nature. 2015;525(7568):265-8.

11. Wang $Y Y$, Cheng $Y$, Chen $K E$, et al. Nitrate transport, signaling, and use efficiency. Annu Rev Plant Biol. 2018;69:85-122.

12. Matsubayashi Y. Posttranslationally modified small-peptide signals in plants. Annu Rev Plant Biol. 2014;65:385-413.

13. Wang G, Fiers M. CLE peptide signaling during plant development Protoplasma. 2010;240:33-43.

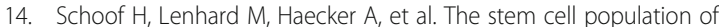
Arabidopsis shoot meristems is maintained by a regulatory loop between the CLAVATA and WUSCHEL genes. Cell. 2000;100(6):635-44.

15. Hirakawa $Y$, Shinohara $H$, Kondo $Y$, et al. Non-cell- autonomous control of vascular stem cell fate by a CLE peptide/receptor system. Proc Natl Acad Sci. 2008;105(39):15208-13.

16. Hirakawa $Y$, Kondo $Y$, Fukuda $\mathrm{H}$. TDIF peptide signaling regulates vascular stem cell proliferation via the WOX4 homeobox gene in Arabidopsis. Plant Cell. 2010;22(8):2618-29.

17. Fisher K, Turner S. PXY, a receptor-like kinase essential for maintaining polarity during plant vascular-tissue development. Curr Biol. 2007;17(12): $1061-6$.

18. Huang S, Li R, Zhang Z, Li L, Gu X, Fan W, et al. The genome of the cucumber, Cucumis sativus L. Nat Genet. 2009:41:1275-81.

19. Cavagnaro PF, Senalik DA, Yang L, Simon PW, Harkins TT, Kodira CD, et al. Genome-wide characterization of simple sequence repeats in cucumber (Cucumis sativus L.). BMC Genomics. 2010;11:569.

20. Li Q, Li H, Huang W, Xu Y, Zhou Q, Wang S, et al. A chromosomescale genome assembly of cucumber (Cucumis sativus L.). Gigascience. 2019;8.

21. Garcia-Mas J, Benjak A, Sanseverino W, Bourgeois M, Mir G, Gonzalez VM, et al. The genome of melon (Cucumis melo L.). Proc Natl Acad Sci U S A. 2012;109:11872-7.

22. Hu L, Liu S. Genome-wide analysis of the MADS-box gene family in cucumber. Genome. 2012:55:245-56.

23. Li Y, Feng S, Ma S, Sui X, Zhang Z. Spatiotemporal expression and substrate specificity analysis of the cucumber SWEET gene family. Front Plant Sci. 2017:8:1855.

24. Liu SQ, Hu LF. Genome-wide analysis of the auxin response factor gene family in cucumber. Genet Mol Res. 2013;12:4317-31.

25. Liu SQ, Liu XH, Jiang LW. Genome-wide identification, phylogeny and expression analysis of the lipoxygenase gene family in cucumber. Genet Mol Res. 2011;10:2613-36. 
26. Xu X, Liu M, Lu L, He M, Qu W, Xu Q, et al. Genome-wide analysis and expression of the calcium-dependent protein kinase gene family in cucumber. Mol Gen Genomics. 2015;290:1403-14.

27. Zhou Y, Hu L, Jiang L, Liu S. Genome-wide identification, characterization, and transcriptional analysis of the metacaspase gene family in cucumber (Cucumis sativus). Genome. 2018:61:187-94.

28. Zhou Y, Hu L, Ye S, Jiang L, Liu S. Genome-wide identification of glutathione peroxidase (GPX) gene family and their response to abiotic stress in cucumber. 3 Biotech. 2018;8(3):159.

29. Zhu YX, Yang L, Liu N, Yang J, Zhou XK, Xia YC, et al. Genome-wide identification, structure characterization, and expression pattern profiling of aquaporin gene family in cucumber. BMC Plant Biol. 2019;19:345.

30. Goad DM, Zhu C, Kellogg EA. Comprehensive identification and clustering of CLV3/ESR-related (CLE) genes in plants finds groups with potentially shared function. New Phytol. 2017;216:605-16

31. Ni J, Clark SE. Evidence for functional conservation, sufficiency, and proteolytic proteolytic processing of the CLAVATA3 CLE domain. Plant Physiol. 2006;140:726-33.

32. Fiers M, Golemiec $E$, van der Schors $R$, et al. The CLAVATA3/ESR motif of CLAVATA3 is functionally independent from the nonconserved flanking sequence. Plant Physiol. 2006;141:1284-92.

33. Kondo T, Sawa S, Kinoshita A, et al. A plant peptide encodede by CLV3 identified by in situ MALDI-TOF MS analysis. Science. 2006:313:845-8.

34. Brand U, Fletcher JC, Hobe M, et al. Dependence of stem cell fate in Arabidops on a feedback loop regulated by ${ }^{C L V 3}$ activity. Science. 2000; 289(5479):617-9.

35. Meng L, Feldman L. CLE14/CLE20 peptides may interact with CLAVATA2/ CORYNE receptor-like kinases to irreversibly inhibit cell division in the root meristem of Arabidopsis. Planta. 2010;232:1061-74.

36. Je Bl, Gruel J, Lee YK, Bommert P, Arevalo ED, Eveland AL, et al. Signaling from maize organ primordia via FASCIATED EAR3 regulates stem cell proliferation and yield traits. Nat Genet. 2016;48:785-91.

37. Fletcher JC, Brand U, Running MP, Simon R, Meyerowitz EM. Signaling of cell fate decisions by CLAVATA3 in Arabidopsis shoot meristems. Science. 1999;283:1911-4

38. Ikeda M, Mitsuda N, Ohme-Takagi M. Arabidopsis WUSCHEL is a bifunctional transcription factor that acts as a repressor in stem cell regulation and as an activator in floral patterning. Plant Cell. 2009;21:3493-505.

39. Jun J, Fiume E, Roeder AH, et al. Comprehensive analysis of cle polypeptide signaling gene expression and overexpression activity in Arabidopis. Plant Physiol. 2010;154:1721-36.

40. Hastwell AH, Gresshoff PM, Ferguson BJ. Genome-wide annotation and characterization of CLAVATA/ESR (CLE) peptide hormones of soybean (Glycine max) and common bean (Phaseolus vulgaris), and their orthologues of Arabidopsis thaliana. J Exp Bot. 2015;66(17):5271-87.

41. Araya $\mathrm{T}$, von Wirén $\mathrm{N}$, Takahashi H. CLE peptides regulate lateral root development in response to nitrogen nutritional status of plants. Plant Signal Behav. 2014;9(7):2029-34.

42. Betsuyaku S, Sawa S, Yamada M. The function of the CLE peptides in plant development and plant-microbe interactions [M]. Arabiopsis Book. 2011;9: e0149.

43. Hsu PD, Scott DA, Weinstein JA, et al. DNA targeting specificity of RNAguided Cas9 nucleases. Nat Biotechnol. 2013;31:827-32.

44. Liu JJ, Sturrock R, Ekramoddoullah AK. The superfamily of thaumatin-like proteins: its origin, evolution, and expression towards biological function. Plant Cell Rep. 2010;29:419-36.

45. Guo B, Wei Y, Xu R, et al. Genome-wide analysis of APETALA2/ EthyleneResponsive Factor (AP2/ERF) gene family in barley (Hordeum vulgare L.). PLOS ONE. 11(9):e0161322. https://doi.org/10.1371/journal.pone.0161322.

46. Oelkers K, Goffard N, Weiller G, et al. Bioinformatic analysis of the CLE signaling peptide family. BMC Plant Biol. 2008;8:1.

47. Zhang Y, Yang S, Song Y, et al. Genome-wide characterization, expression and functional analysis of CLV3/ESR gene family in tomato. BMC Genomics. 2014;15:1-12.

48. Cock J, McCormick S. A large family of genes that share homology with CLAVATA3. Plant Physiol. 2011;126:939-42.

49. Gao X, Guo Y. CLE peptides in plants: proteolytic processing, structureactivity relationship, and ligand-receptor interaction F. J Integr Plant Biol. 2012;54:738-45
50. Gancheva MS, Dodueva IE, Lebedeva MA, et al. Identification, expression, and functional analysis of CLE genes in radish (Raphanus sativus L.) storage root. BMC Plant Biol. 2016;16(1):7.

51. Strabala TJ, O'donnell PJ, Smit AM, et al. Gain-of-function phenotypes of many CLAVATA3/ESR genes, including four new family members, correlate with tandem variations in the conserved CLAVATA3/ESR domain. Plant Physiol. 2006;140:1331-44.

52. Clark SE, Running MP, Meyerowitz EM. CLAVATA3 is a specific regulator of shoot and floral meristem development affecting the same processes as CLAVATA1. Development. 1995;121:2057-67.

53. Fan CC, Wu YD, Yang QY, et al. A novel single-nucleotide mutation in a CLAVATA3 gene homolog controls a multilocular silique trait in Brassica rapa L. Mol Plant. 2014;7(12):1788-92.

54. Yang Y, Kaiyu Z, Chuchuan F, et al. Precise editin of CLAVATA genes in Brassica napus L. regulates multilocular silique development. Plant Biotechnol J. 2018;16:1322-35.

55. Li S, Pan Y, Wen C, et al. Integrated analysis in bi-parental and natural populations reveals CSCLAVATA3 (CSCLV3) underlying carpel number variations in cucumber. Theor Appl Genet. 2016;129:1007-22.

56. Liu N, Cheng F, Zhong Y, Guo X. Comparative transcriptome and coexpression network analysis of carpel quantitative variation in Paeonia rockii. BMC Genomics. 2019:20:683.

57. Lamesch P, Berardini TZ, Li D, Swarbreck D, Wilks C, Sasidharan R, et al. The Arabidopsis information resource (TAIR): improved gene annotation and new tools. Nucleic Acids Res. 2012;40:D1202-10.

58. Gasteiger E, Gattiker A, Hoogland C, Ivanyi I, Appel RD, Bairoch A. ExPASy: the proteomics server for in-depth protein knowledge and analysis. Nucleic Acids Res. 2003;31:3784-8.

59. Larkin MA, Blackshields G, Brown NP, Chenna R, McGettigan PA, McWilliam $H$, et al. Clustal W and Clustal X version 2.0. Bioinformatics. 2007;23:2947-8.

60. Hu B, Jin J, Guo AY, Zhang H, Luo J, Gao G. GSDS 2.0: an upgraded gene feature visualization server. Bioinformatics. 2015;31:1296-7.

61. Bailey TL, Boden M, Buske FA, Frith M, Grant CE, Clementi L, et al. MEME SUITE: tools for motif discovery and searching. Nucleic Acids Res. 2009;37: W202-8.

62. Li L, Stoeckert CJ Jr. Roos DS OrthoMCL: identification of ortholog groups for eukaryotic genomes. Genome Res. 2003;13:2178-89.

63. Zhang Z. Yu J evaluation of six methods for estimating synonymous and nonsynonymous substitution rates. Genomics Proteomics Bioinformatics. 2006:4:173-81.

64. Zhang Z, Xiao J, Wu J, Zhang H, Liu G, Wang X, et al. ParaAT: a parallel tool for constructing multiple protein-coding DNA alignments. Biochem Biophys Res Commun. 2012;419:779-81.

65. Koch MA, Haubold B. Mitchell-olds T comparative evolutionary analysis of chalcone synthase and alcohol dehydrogenase loci in Arabidopsis, Arabis, and related genera (Brassicaceae). Mol Biol Evol. 2000;17:1483-98.

66. Smoot ME, Ono K, Ruscheinski J, Wang PL, Ideker T. Cytoscape 2.8: new features for data integration and network visualization. Bioinformatics. 2011; 27:431-2.

67. Wei G, Tian P, Zhang F, Qin H, Miao H, Chen Q, et al. Integrative analyses of nontargeted volatile profiling and transcriptome data provide molecular insight into VOC diversity in cucumber plants (Cucumis sativus). Plant Physiol. 2016;172:603-18

68. Chen $\mathrm{C}$, Chen $\mathrm{H}, \mathrm{He} \mathrm{Y}$, et al. TBtools, a toolkit for biologists integrating various biological data handling tools with a user-friendly interface. BioRxiv. 2018;289660.

\section{Publisher's Note}

Springer Nature remains neutral with regard to jurisdictional claims in published maps and institutional affiliations. 